\title{
Espaços públicos arborizados enquanto elemento potencializador de saúde
}

\author{
Wooded areas as public health enhacer element
}

Mariel Stenia Vanina Vianna, ${ }^{1}$ Nilvane Teresinha Ghellar Müller, ${ }^{1}$ Narciso Vieira Soares,'
Zaleia Prado de Brum, ${ }^{1}$ Denilson da Silva Machado'
'Universidade Regional Integrada do Alto Uruguai e Missões (URI), Santo Ângelo, RS, Brasil.

Recebido em: 21/08/2016 / Aceito em: 27/09/2016 / Publicado em: 18/10/2016

vaninaribas@hotmail.com

\section{RESUMO}

A crescente expansão urbana vem interferindo significativamente na distribuição de áreas verdes nas cidades; essas têm a função de aprimorar a saúde, melhorando a qualidade de vida das pessoas. Objetivo: caracterizar as áreas verdes existentes na zona urbana do município e identificar potencialidades, enquanto ambiente para promoção da saúde. Método: estudo quali-quantitativo e descritivo, realizado na cidade de Santo Ângelo/RS. Foram caracterizadas cada uma das áreas verdes públicas urbanas (praças) existentes no município, através de levantamento da vegetação arbórea, além de investigar a existência de plantas medicinais. Para a classificação dos vegetais, foram utilizadas bibliografias já existentes. Quanto à constatação das plantas autorizadas pelo SUS, realizou-se uma busca no site da Secretaria Nacional da Saúde, para a posterior verificação. Resultados e Considerações Finais: constatou-se que, na cidade de Santo Ângelo/RS, existem 8 (oito) áreas verdes públicas, onde observou-se a existência de um número menor de espécies nativas em relação às exóticas. O número total de espécies existentes em cada praça varia de 14 a 26; para as espécies nativas, este número encontra-se entre 4 a 15 , enquanto que para as espécies exóticas oscila de 8 a 14. Ainda foram encontradas diversas espécies arbóreas que apresentam potencial medicinal, sendo estes os mais variados. Dentre as 58 espécies encontradas algumas estão citadas na lista de plantas medicinais de interesse

\section{ABSTRACT}

The increasing urban sprawl is significantly interfering with green areas distribution in cities. These are meant to improve population health and quality of life. Objective: this study aimed to characterize the existing green areas in the municipality and identify potential as setting for health promotion. Method: qualitative and quantitative and descriptive study, conducted in the city of Santo Ângelo/RS. Each of the urban public green areas were characterized (squares) in the municipality, through a survey of trees, and to investigate the existence of medicinal plants. For the classification of bioactive plant we used existing bibliographies. As for the realization of plants authorized by the SUS, we performed a search on the National Health Department site for further verification. Results and Closing Remarks: it was found that in the city of Santo Ângelo/RS there are eight (8) public green areas named squares where it was observed that there are fewer native species for each exotic in every street of the urban area of Santo Ângelo. The total number of species in each square ranges from 14 to 26. For the native species this number is between 4-15 while for the exotic species ranges from 8 to 14. We also found several tree species with medicinal potential, which are the most varied. Among the 58 species found some are named in the list of medicinal plants of interest to the Unified Health System (SUS) as is the case with Bahuinia Variegata, Eugenia uniflora, Persea americana and Psidium guajava. do Sistema Único de Saúde (SUS), como é o caso da Bahuinia Variegata, Eugenia uniflora, Persea americana e Psidium guajava, que auxiliam na promoção da saúde.

Palavras-chave: Plantas medicinais; Áreas verdes; Promotion.

Keywords: Medical plants, Green Area, Health Promoção da Saúde. 


\section{INTRODUÇÃO}

Os impactos produzidos pela agressão do homem à natureza vêm sendo objeto de estudos e reflexões em diversos âmbitos, na perspectiva de buscar a sustentabilidade da vida humana no planeta. A partir da Revolução Industrial, as cidades se tornaram os principais polos da economia, gerando o processo de urbanização, exemplo de uma grande apropriação do espaço natural; sendo assim, as cidades cresceram e estrangularam as áreas verdes e os rios que entremeiam os seus bairros. Essa crescente e veloz expansão urbana vem interferindo intensamente no planejamento da ocupação do solo, afetando significativamente a distribuição de áreas verdes nas cidades. Essas têm a função de melhorar a qualidade de vida seja para fins de lazer, de equilíbrio climático, da preservação ambiental e construção da paisagem urbana. A vegetação urbana assume um papel preponderante na manutenção da qualidade ambiental nesse espaço, tanto em seus aspectos ecológicos, quanto socioeconômicos. ${ }^{1}$

Nas discussões sobre a cidade e sua relação com a natureza, situa-se a questão da qualidade de vida das pessoas que nela habitam. Para que a população tenha qualidade de vida, depende de suas condições de existência, do seu acesso a certos bens e serviços econômicos e sociais: emprego e renda, educação básica, alimentação adequada, acesso a bons serviços de saúde, saneamento básico, habitação, transporte de boa qualidade etc. É bom lembrar que o conceito de bem-estar, de qualidade de vida, varia de sociedade para sociedade, de acordo com cada cultura. ${ }^{2}$

Qualidade de vida e saúde são dois conceitos muito ligados. Em uma concepção contemporânea, saúde é o resultado de um processo de produção social, que expressa a qualidade de vida de uma população. A saúde é considerada produto social, isto é, resultado das relações entre os processos biológicos, ecológicos, culturais e econômico-sociais que acontecem em determinada sociedade e que geram as condições de vida das populações. ${ }^{2} \mathrm{~A}$ abordagem desse novo conceito de saúde alicerça-se nas concepções da Carta de Ottawa, elaborada na I Conferência Internacional de Promoção da Saúde, realizada no Canadá, em 1986, ao afirmar que as condições e os requisitos para a saúde são a paz, a educação, a moradia, a alimentação, a renda, um ecossistema estável, a justiça social e a equidade.

A Constituição brasileira declara a saúde como direito social de todos os cidadãos, consequentemente, um dever do Estado. A saúde passa a ser entendida para além da área de prestação de serviços e de prevenção e tratamento de doenças, sendo garantida a partir de políticas sociais e econômicas que visem à redução do risco de doença e de outros agravos e ao acesso universal e igualitário às ações e serviços para sua promoção, proteção e recuperação" ${ }^{3}$ Nessa perspectiva, circunscreve-se ao trabalho em saúde, ações de promoção da qualidade de vida, prevenção de doenças, ações de vigilância sanitária, epidemiológica ambiental e saúde do trabalhador, a condução de planos, redes e sistemas além de ações intersetoriais e políticas no âmbito da preservação da saúde.

A promoção da saúde é um processo, através do qual a população se capacita e busca os meios para conseguir controlar os fatores que favorecem seu bem-estar individual e coletivo; não a tornando vulnerável ao adoecimento e prejudicando sua qualidade de vida. ${ }^{4}$

As praças são espaços livres públicos urbanos destinados ao lazer e ao convívio da população, acessíveis aos cidadãos e livres de veículos. Nessas áreas, pode-se encontrar boa parcela dos indivíduos arbóreos nas cidades, porém, na prática, é possível que não representem boa diversidade de espécies nem respeitem aos valores culturais, ambientais e de memória da cidade. ${ }^{1} \mathrm{E}$, diante desta visão global acerca do tema, é clara a importância destas áreas na formação de uma cidade, pois além disso, exercerem papel importante na ornamentação urbana, exercem outras funções vitais, como: higiênica, paisagística, estética, plástica, de recreação, de valorização econômica das propriedades ao entorno, de valorização da qualidade de vida local e de defesa e recuperação do meio ambiente. ${ }^{5}$

As iniciativas em direção à preservação e recomposição de vegetais requerem conhecimentos de florística, fitossociologia e também da ecologia de suas espécies componentes. ${ }^{6}$ Os estudos arbóreos e arbustivos fornecem informações acerca da estrutura das comunidades e de algumas populações, bem como o conhecimento da flora regional, subsidiando, dessa forma, o manejo, a recuperação e/ou a conservação dos ecossistemas. Portanto, pode constituir o ponto de partida para nortear atividades conservacionistas. ${ }^{7}$

Em termos de biodiversidade vegetal, o Brasil apresenta grande diversidade de espécies, correspondendo a $22 \%$ do total de espécies vegetais do planeta, representando enorme vantagem competitiva em relação a outros países. É considerado um dos países com maior perspectiva para a exploração econômica da biodiversidade vegetal do planeta. ${ }^{8}$

As plantas medicinais desde os mais remotos tempos fazem parte do cenário mundial e, seu uso, em determinadas comunidades foi o principal recurso terapêutico utilizado para tratar a saúde das pessoas e de suas famílias. ${ }^{9} \mathrm{O}$ homem experimentava espécies e as diferentes partes da planta como as folhas, a casca, as sementes, a raiz, as flores e as frutas, em busca da cura de doenças. ${ }^{10}$ Entretanto, com os avanços ocorridos no âmbito das ciências da saúde, novas maneiras de tratar e curar as doenças foram surgindo. Uma delas consiste no uso de medicamentos industrializados, gradativamente introduzidos no cotidiano das pessoas por meio de campanhas publicitárias que prometem curar as mais diversas doenças. ${ }^{11}$

A população, por vez, desconhece os benefícios que inúmeras espécies vegetais podem proporcionar ao ser humano. Por outro lado, algumas poucas pessoas detêm conhecimentos empíricos acerca da ação de certos vegetais. O conhecimento e a utilização de plantas acompanham a evolução humana através dos tempos. As informações sobre o uso e as propriedades das plantas acumuladas ao longo dos séculos, permite sua utilização para as mais diversas finalidades, especialmente no tratamento de doenças.

A relação nacional de plantas medicinais de interesse ao SUS (RENISUS) é constituída de espécies vegetais com potencial de avançar nas etapas da cadeia produtiva e de gerar produtos de interesse ao Sistema Único de Saúde (SUS) e ao Ministério da Saúde. As 
espécies vegetais foram pré-selecionadas por regiões que referenciavam seu uso por indicações e de acordo com as categorias do Código Internacional de Doenças (CID-10). Essa parte inicial do trabalho foi realizada por técnicos da ANVISA e do Ministério da Saúde, profissionais de serviços, pesquisadores da área de plantas medicinais e fitoterápicos, vinculados à área da saúde, representando as diversas regiões brasileiras. ${ }^{12}$

Ao considerar a importância da realização de distintos estudos com ênfase na bioatividade das espécies vegetais, ocorrem grandes possibilidades para proporcionar novas descobertas no tratamento de diversas enfermidades e ampliar o conhecimento relacionado ao saber tradicional das comunidades. Desta forma, o presente estudo objetivou caracterizar as áreas verdes existentes na zona urbana do Município e identificar potencialidades enquanto ambiente para promoção da saúde. Para tal, buscou-se verificar, entre as espécies vegetais bioativas encontradas quais, aparecem na lista do Sistema Único de Saúde (SUS).

\section{METODOLOGIA}

É um estudo quali-quantitativo, descritivo realizado na cidade de Santo Ângelo/RS, a qual situa-se na encosta ocidental do Planalto Médio Rio-Grandense, na Mesorregião do Noroeste Rio-Grandense, zona fisiográfica. Está localizada na bacia do rio ljuí e na interseção das coordenadas $28^{\circ} 17^{\prime} 56^{\prime \prime}$ de latitude Sul e 54 ${ }^{\circ} 15^{\prime} 46^{\prime \prime}$ de longitude Oeste, do meridiano de Greenwich. Está distante $459 \mathrm{~km}$ da capital gaúcha, Porto Alegre. Limita-se ao Norte, com Giruá; ao Sul, com Entre-ljuís e Vitória das Missões; a Leste e Nordeste, Catuípe; a Oeste, com Guarani das Missões; e a Noroeste, com Sete de Setembro.

A presente pesquisa foi realizada de março a novembro de 2014, período em que foram consideradas as áreas verdes públicas urbanas (praças) existentes no município. Neste foi realizada a caracterização de cada praça, através de levantamento da vegetação arbórea, além de investigar a existência de plantas bioativas.

Para a realização da pesquisa qualitativa foram observados e fotografados o estado de conservação e as práticas recreativas que são exercidas nas áreas de abrangência da pesquisa, visando retratar as situações existentes, através de um formulário próprio para orientação. Após, coletou-se informações sobre o estado da área, tipos de pisos, iluminação, equipamentos de serviços e lazer, monumentos e elementos arquitetônicos significativos e o estado de conservação geral do local. Para o levantamento das espécies existentes nos locais, foram identificadas todas as plantas arbóreas, sendo elas nativas ou exóticas e sua bioatividade.

Após estes levantamentos verificou-se, dentre os vegetais encontrados, quais das plantas bioativas encontram-se citados na lista do Sistema Único de Saúde (SUS). Para a classificação dos vegetais bioativos foram utilizadas bibliografias já existentes. Quanto à constatação das plantas autorizadas pelo SUS, foi feita uma busca no site da Secretaria Nacional da Saúde para a posterior verificação.

\section{RESULTADOS E DISCUSSÃO}

Constatou-se que na cidade de Santo Ângelo/RS existem 8 (oito) áreas verdes públicas nomeadas praças (Tabela 1), onde foram encontradas espécies nativas e também exóticas, predominando, na maioria das praças, as exóticas.

Tabela 1 - Levantamento de praças e suas espécies arbóreas no município de Santo Ângelo/RS.

\begin{tabular}{lccc}
\hline Denominação & $\begin{array}{c}\mathbf{N}^{\circ} \text { Total de } \\
\text { Espécies }\end{array}$ & $\begin{array}{c}\text { Espécies } \\
\text { Nativas }\end{array}$ & $\begin{array}{c}\text { Espécies } \\
\text { Exóticas }\end{array}$ \\
\hline Praça Castelo Branco & 25 & 11 & 14 \\
Praça Dário Beltrão & 23 & 10 & 13 \\
Praça João Carlos Kist & 14 & 6 & 8 \\
Praça Leônidas Ribas & 25 & 12 & 13 \\
Praça Pinheiro Machado & 26 & 15 & 11 \\
Praça Raimundo Ribeiro Carneiro & 15 & 4 & 11 \\
Praça Raul Oliveira & 14 & 11 & 13 \\
Praça Três Mártires & 20 & 8 & 12 \\
\hline
\end{tabular}

Conforme a tabela 1, observa-se, com exceção de uma praça, a existência de um número menor de espécies nativas em relação às exóticas, em todas as demais praças da zona urbana de Santo Ângelo. O número total de espécies existentes em cada praça varia de 14 a 26; para as espécies nativas este número encontra-se entre 4 a 15, enquanto que para as espécies exóticas oscila de 8 a 14 .

Das praças visitadas, as com melhores condições sanitárias e de acessibilidade, foram a praça do Castelo Branco, a praça Diário Beltrão, João Carlos Kist, Leônidas Ribas e a Pinheiro Machado. Nestas, observaram-se várias opções de lazer, como playground, academias ao ar livre, quadras de futebol e pistas de skate. Com exceção da Praça João Carlos Kist, todas as outras áreas apresentam ampla diversidade vegetal, onde encontram-se árvores de grande e médio porte, além gramados em boas condições. Estas Praças ainda contam com uma boa iluminação, banheiros e diversas lixeiras.

Por outro lado, a Praça Raimundo Ribeiro, Três Mártires e a Praça Raul Oliveira apresentam um estado bastante precário, pois as poucas estruturas contidas em seus limites necessitam de manutenção. Nas mesmas, a vegetação dominante é exótica, no entanto, ao contrário das Praças Raimundo Ribeiro e Três Mártires, a praça Raul Oliveira apresenta boa iluminação, todavia esta seja menor que as outras analisadas pelo estudo.

Durante os finais de semana, foram realizadas visitas em todas as praças para verificar as atividades desenvolvidas nas mesmas. Na maioria delas observou-se uma grande quantidade de pessoas, circulando nas praças, algumas realizando alguma atividade física, como corrida, caminhada ou exercícios nas academias ao ar livre (Praça Dário Beltrão, Leônidas Ribas e Raimundo Ribeiro). Verificaram-se também muitas crianças brincando no playground, jogando futebol, basquete e andando de bicicleta. A maioria das praças é um local de encontro de pessoas nos finais de pessoas, onde as mesmas levam chimarrão para dividir com amigos e familiares. A vegetação arbórea presente nas áreas verdes atua beneficamente à população, promovendo 
bem-estar pelo verde de suas folhas e o colorido das flores, além do odor agradável que algumas espécies liberam naquele local. Ainda fornece sombra, abrigo quando há chuvas brandas, alimento no caso das frutíferas e, promovem um microclima agradável a todos que frequentam aquele espaço.

Tal realidade observada confere com o que defende Lynch (apud PEREIRA) ${ }^{13}$ que: "as praças são espaços de encontro e lazer dos transeuntes, são locais de escape dentro do contexto urbano, onde proporcionar o bem-estar dos indivíduos é o principal objetivo". Para tal, o mobiliário e os equipamentos urbanos como bancos, iluminação, fontes, cobertura vegetal, sombreamento são indispensáveis para atraírem a população e garantirem conforto no espaço público. Para Leitão, ${ }^{14}$ as praças constituem unidades urbanísticas fundamentais para a vida urbana. Tanto os aspectos físicos, quanto os naturais da praça são de extrema importância para conservação do meio ambiente e manutenção da qualidade de vida dos moradores destes bairros.

Estas praças, jardins públicos, parques e áreas verdes em geral constituem ambientes muito relevantes para a garantia de equilíbrio ambiental e a manutenção da qualidade de vida da população que os rodeia. De um modo geral, pode-se dizer que as praças são espaços livres urbanos utilizados como local público. São pontos de encontro cuja principal função é de incentivar a socialização e o lazer (LIMA et al., 1994)..$^{15}$ Demattê $^{16}$ ainda afirma que, por fazer parte da vida comunitária, a praça reflete os costumes, as crenças e outros aspectos da cultura de seus usuários. Planejada ou não, ela tem valores simbólicos ligados aos seus frequentadores.

Em sua complexa diversidade, existe grande número de plantas que são utilizadas pelas populações para o tratamento de diversas enfermidades, tanto para seres humanos quanto para animais domésticos. ${ }^{17}$ Há cerca de 3000 anos antes de Cristo, os chineses já utilizavam e cultivavam ervas medicinais, que hoje ainda são usadas com eficácia, tanto na medicina popular, como por laboratórios de produtos farmacêuticos. ${ }^{18} \mathrm{~A}$ utilização de plantas para o tratamento da saúde permanece até os dias de hoje, fazendo parte da cultura de diferentes comunidades populacionais. De acordo com Rodri- gues,$^{19}$ tendo em vista a importância de sanar, ou pelo menos de amenizar os problemas socioeconômicos da população brasileira, é crescente a preocupação em se estabelecer grupos de plantas medicinais para pesquisas, suas potencialidades, usos e meios de conservação desses recursos genéticos. Atualmente, o cultivo das ervas medicinais é um processo muito importante para a conservação das espécies vegetais, porque a retirada de plantas nativas de seu ambiente natural tem levado, em muitos casos, à redução drástica das populações destas espécies. ${ }^{20}$

No levantamento florístico (Figura 1), foram encontradas 20 famílias arbóreas e 50 espécies. As mais encontradas foram: Myrtaceae com 12,07\%, Fabaceae com 10,17\% e Areacaceae e Bignonaceae com 8,47\%.

A família Arecaceae, conhecida como das palmeiras foram um dos principais troncos da evolução das monocotiledôneas, sendo constituída, atualmente, por 252 gêneros e aproximadamente de 2.600 espécies. ${ }^{21}$ No Brasil, ocorrem naturalmente 38 gêneros e cerca de 270 espécies. ${ }^{22}$

As Arecaceae representam a terceira família botânica mais importante para o ser humano, por envolver diversas espécies com efeitos bioativos. Segundo Souza e Lorenzi $i^{23}$ muitas das espécies que pertencem a esta família destacam-se como ornamentais, principalmente devido ao porte e à folhagem, sendo um elemento muito comum no paisagismo de ruas, praças e residências; outras são, alimentícias ou fornecem fibras e material de cobertura (JUDD et al., 2009). ${ }^{24}$

Do ponto de vista bioativo, destacam-se diversas espécies utilizadas como ornamentais, principalmente devido ao porte e à folhagem, sendo um elemento muito comum no paisagismo de ruas, praças e residências. Praticamente todas as palmeiras possuem potencial ornamental, mas algumas das mais utilizadas são as palmeiras-leque (Licuala grandis), palmeiras-reias ( $A r$ chontophoenix spp) e as palmeiras-fénix (Phoenix spp). As palmeiras são ainda utilizadas, tanto em construções rústicas, como na alimentação.

A família Bignoniaceae possui um grande potencial ornamental, segundo Souza e Lorenzi ${ }^{23}$. Estão incluídas muitas árvores que são utilizadas como fonte de ma-

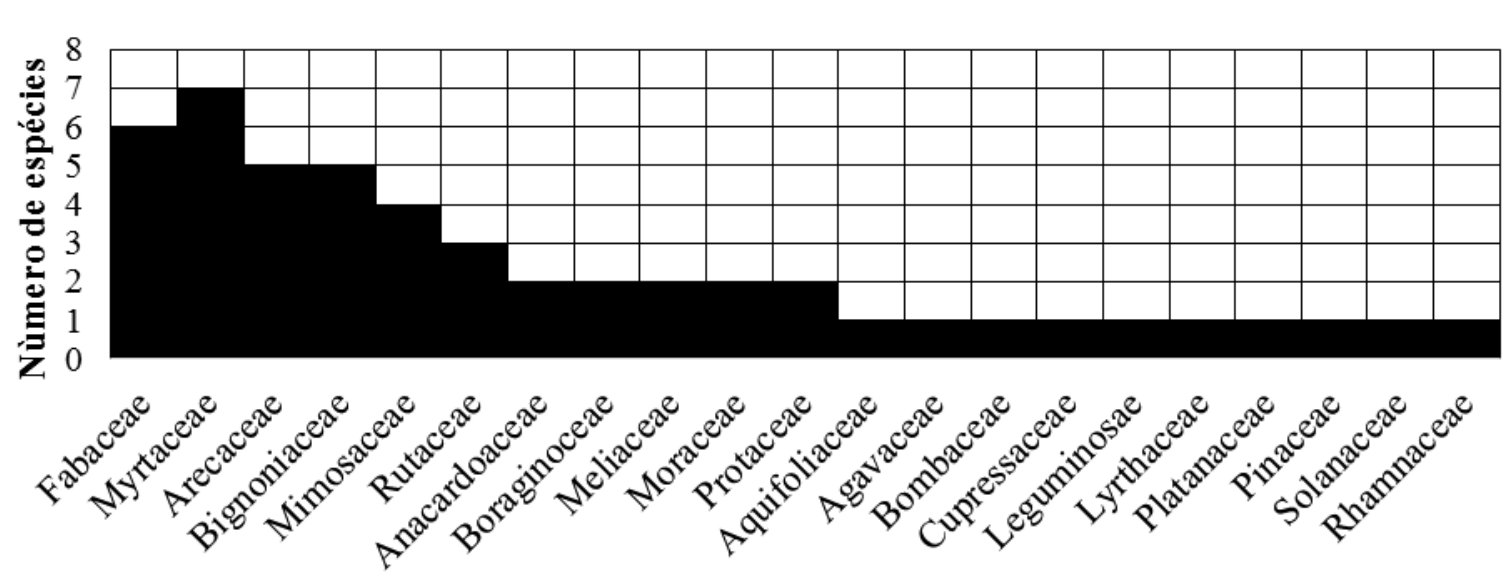

Famílias

Figura 1 - Famílias arbóreas e número de espécies amostradas. 
deira - como os ipês (Tabebuia spp) e os jacarandás ou carobas (Jacaranda spp) - e que também estão entre as mais populares para utilização em arborização urbana e de rodovias na região sul. Essas espécies possuem atrativos que justificam sua popularidade, entre eles o porte compatível com os espaços disponíveis no ambiente urbano e o aspecto variável ao longo do ano. ${ }^{25}$

Já, a família Myrtaceae apresenta grande potencial econômico, muitas de suas espécies são utilizadas na alimentação, como, as espécies de Psidium guajava L. da goiaba e Eugenia uniflora L. da "pitanga", consumidas em forma de suco, doces, geleias e sorvetes. ${ }^{26}$ As espécies nativas também são pródigas na produção de frutos no decorrer do ano, disponibilizando alimento para a fauna, tanto em ecossistemas campestres, quanto florestas.

Muitas dessas espécies também produzem frutos agradáveis ao paladar humano e que podem ser consumidos frescos ou nas mais variadas formas de preparo, como em sucos, geléias, sobremesas e licores. A grande diversidade de espécies nativas também oferece muitas opções para cultivo de plantas ornamentais no paisagismo de espaços urbanos. ${ }^{25}$ Também apresentam importância ecológica, pois seus frutos suculentos e carnosos são fontes de alimento à fauna silvestre. Muitos animais que se alimentam desses frutos acabam veiculando a dispersão das sementes e favorecendo a sobrevivência e permanência dessas espécies. A goiabeira (Psidium guajava) produz frutos consumidos in natura ou preparados em diversos tipos de doces.

As espécies nativas brasileiras geralmente são frutíferas com elevada importância comercial, sendo apreciadas pela fauna e pelas pessoas. ${ }^{27}$ Nos ecossistemas onde habitam são facilmente reconhecíveis por causa do caule, que é tipicamente descamante, e das folhas e dos ramos, que, quando injuriados, liberam odor característico. A floração em muitas espécies nativas é abundante e representa um recurso alimentar disponível para os polinizadores ao longo do ano inteiro, já que a alta diversidade existente nas matas com araucária tem como consequência a existência de espécies férteis em todas as estações. ${ }^{25}$

No Brasil ocorrem 212 gêneros nativos e 2.732 espécies da família Fabaceae, estando entre as famílias mais ricas na maioria dos ecossistemas brasileiros. Possui importante aplicação na adubação verde, principalmente considerando a associação com bactérias do gênero Rhizobium, fixadoras de nitrogênio, que produzem pequenos nódulos nas raízes. Inúmeras são as Fabaceae utilizadas como ornamentais, sendo a principal família utilizada na arborização urbana, no Brasil. Destacando-se a tipuana (Tipuana tipu), sibipiruna (Caesalpinia pluviosa), flamboyant (Delonix regia), pata-de-vaca (Bauhinia variegata). ${ }^{24,23}$

Diversas espécies produzem madeira de excelente qualidade, neste trabalho representado pela canafístula (Peltophorum dubium). Na Mata Atlântica, muitas são as espécies de Fabaceae nativas, mas são bem perceptíveis e conhecidas àquelas que ocorrem nas bordas e locais alterados, como é o caso do Guapuruvú (Schizolobium parahyba), com madeira macia é utilizada pelos índios para a construção de canoas. Nas matas ciliares merece destaque o ingá (/nga spp.), com diversas espécies com frutos comestíveis, muito procurados por macacos e outros animais. ${ }^{23}$

\section{CONSIDERAÇÕES FINAIS}

As áreas verdes da cidade de Santo Ângelo são muito importantes para a população em geral, pois elas oferecem contato a um ambiente natural que pode oferecer a melhora da qualidade de vida dos cidadãos. Nas mesmas identificaram-se diversas espécies arbóreas que apresentam potencial medicinal, sendo estes os mais variados. Dentre as 58 espécies encontradas algumas se encontram citadas na lista de plantas medicinais de interesse do Sistema Único de Saúde (SUS) como é o caso da Bahuinia Variegata, Eugenia uniflora, Persea americana e Psidium guajava.

\section{REFERÊNCIAS}

1. Souza, AL, Ferreira, RA, Mello, AA, Plácio, DR, Santos, Carla ZA, Graça, Dalva AS, Júnior, Pedro PA, Barretto, Soraia SB, Dantas, Jolly DM, Paula, José WA, Silva, TL \& Gomes, Lucas PS. Diagnóstico quantitativo e qualitativo da arborização das praças de Aracajú, SE. Revista Árvore. 2011;35(6):1253-63. doi: 10.1590/S0100-67622011000700012.

2. Henrique, Wendel. Direito à natureza na cidade. Salvador: EDUFBA, 2009. doi: 10.7476/9788523209117.

3. BRASIL. Constituição da República Federativa do Brasil de 1988. Disponível em: http://www.planalto.gov.br/ccivil_03/ Constituicao/Constituicao.htm

4. Ottawa. Carta de Ottawa: primeira conferência internacional sobre promoção da saúde. Disponível em: http://bvsms. saude.gov.br/bvs/publicacoes/carta_ottawa.pdf.

5. Viana, ÁL, Lopes, MC, Neto, NFAL, Kudo, SA, Guimarães, DFS, Mari, MLG. Análise da percepção ambiental sobre os parques urbanos da cidade de Manaus, Amazonas. Revista Monografias Ambientais - REMOA 2014;13(5):4044-62. doi: $10.5902 / 2236130815179$.

6. Santos, K, Kinoshita, LS. Flora Arbustivo-Arbórea do Fragmento de Floresta Estacional Semidecidual do Ribeirão Cachoeira, Município de Campinas, SP. Acta Botânica Brasileira 2033;17(3):325-41. doi: 10.1590/S0102-33062003000300001.

7. Barbosa, MD. Florística e fitossociologia de espécies arbóreas e arbustivas. Revista Árvore 2012;36(5):851-8. doi: 10.1590/S0100-67622012000500007.

8. Silva, KM, Bortoluzzi, RLC, Gomes, JP, Mantovani, A. Espécies bioativas em áreas úmidas do Planalto Catarinense. Revista Brasileira de Plantas Medicinais 2013;15(4):483-93. doi: 10.1590/S1516-05722013000400003.

9. Oliveira, LAR, Machado, RD, Rodrigues, AJL. Levantamento sobre o uso de plantas medicinais com a terapêutica anticâncer por pacientes da unidade oncológica de Anápolis. Revista Brasileira de Plantas Medicinais 2014;16(1):32-40. doi: 10.1590/S1516-05722014000100005.

10. Schiedeck, G. Aproveitamento da biodiversidade regional de plantas bioativas para a sustentabilidade dos agricultores de base ecológica na região sul do RS. Projeto de Pesquisa do Macroprograma 6 - Apoio ao Desenvolvimento da Agricultura Familiar e à Sustentabilidade do Meio Rural. Pelotas: Texto Mimiografado, 2006.

11. Heisler, EV. Saber popular sobre a utilização da planta Anredera Cordifolia (Folha Gorda). Revista de Enfermagem 2012;21(4):937-44. doi: 10.1590/S010407072012000400026

12. Brasil. Ministério da Saúde Elabora Relação de Plantas Medicinais de Interesse ao SUS. 2009. Disponível em: http:// 
bvsms.saude.gov.br/bvs/sus/pdf/marco/ms_relacao _ plantas_medicinais_sus_0603.pdf

13. Pereira, MMDCE. Praças Públicas Sustentáveis: Caso de renovação das praças. 142 f. Dissertação (Mestrado em Arquitetura) - Universidade Técnica de Lisboa Instituto Superior Técnico, Lisboa, p. 142, 2008. Disponível em: https://fenix. tecnico.ulisboa.pt/downloadFile/395137888693/Tese.pdf

14. Leitão, L. As Praças Que A Gente Tem, as praças que a gente quer. Manual de procedimento para intervenção em praças. Secretária de Planejamento Urbanismo e Meio Ambiente, Recife, 2002.

15. Lima, AMLP; Cavalheiro, F, Nucci, JC, Sousa, MALB, Fialho, N, Del Picchia, PCD. Problemas de utilização na conceituação de termos como espaços livres, áreas verdes e correlatos. In: Congresso de Arborização Urbana, 2, 1994. Disponível em: <http://www.labs.ufpr.br/site/wpcontent/uploads/2014/07/ lima_anaisdecongressos_cbau_1994.pdf>.

16. Demattê, MESP. Princípios de paisagismo. ed. $2^{\text {a Jaboticabal: }}$ IUNEP, p. 104, 1997

17. Ming, LC. Levantamento das plantas medicinais na Reserva Extrativista Chico Mendes, Acre.Tese (Doutorado) Universidade Estadual Paulista, Botucatu, p.175, 1995

18. Rodrigues, VEG, Carvalho, DA. Levantamento etnobotânico de plantas medicinais do domínio cerrado na região do Alto Rio Grande - Minas Gerais 2001;25(1):102-23.

19. Rodrigues, VEG. Levantamento florístico e etnobotânico de plantas medicinais dos cerrados na região do Alto Rio Grande - Minas Gerais [dissertação]. Lavras: Universidade Federal de
Lavras. p. 235, 1998.

20. Reis, MS, Mariot, A, Steenbock, W. Diversidade e domesticação de plantas medicinais. In: Simões, CMO, Schenkel, EP, Gosman, G, Mello, JCP, 2003.

21. Dransfield, J, Uhl, NW, Asmussen, CB, Baker, WJ, Harley, MM \& Lewis, CE. Genera Palmarum: the evolution and classification of palms. London: Royal Botanical Garden, p.732, 2008.

22. Lorenzi, H, Noblick, LR, Kahn, F \& Ferreira, E. Flora brasileira: Arecaceae (Palmeiras). Nova Odessa: Instituto Plantarum, p. 382, 2010.

23. Souza, VC, Lorenzi, H. Botânica sistemática: guia ilustrado para identificação das famílias de fanerógamas nativas e exóticas no Brasil, baseado em APG III. 3. ed. Nova Odessa: Instituto Plantarum, 2012.

24. Judd, WS, Campbell, CS, Kellogg, EA, Stevens, PF, Donoghue, MJ. Sistemática vegetal: um enfoque filogenético. Porto Alegre: Editora Artmed. ed. 3a, 2009.

25. Judd, WS, Campbell, CS, Kellogg, EA \& Stevens, PF. Plant Systematics - a phylogenetic approach. Massachusetts: Sinauer Associates, p. 465, 1999.

26. Lorenzi, H, Bacher, L, Lacerda, M, Sartori, S. Frutas brasileiras e exóticas cultivadas (de consumo in natura). São Paulo: Instituto Plantarum de Estudos da Flora, p.672, 2006.

27. Carvalho, PER. Espécies arbóreas brasileiras. Vol. 4. Embrapa Florestas, Colombo. p.644, 2010.

28. Prefeitura Municipal de Santo Ângelo, 2014. Disponível em http://www.santoangelo.rs.gov.br.

Como citar: VIANNA, Mariel Stenia Vanina et al. Espaços públicos arborizados enquanto elemento potencializador de saúde. Cinergis, Santa Cruz do Sul, v. 17, n. 4, out. 2016. ISSN 2177-4005. Disponível em: <https://online.unisc.br/seer/index.php/ cinergis/article/view/8145 >. Acesso em: 11 out. 2016. doi:http://dx.doi.org/10.17058/cinergis.v17i4.8145. 